\section{SOI: $1.1 /$ TAS DOI: $10.15863 /$ TAS International Scientific Journal Theoretical \& Applied Science}

WMO at THQ Pasrur district Sialkot Pakiaqat baskketbella@gmail.com

p-ISSN: 2308-4944 (print) e-ISSN: 2409-0085 (online)

Year: 2018 Issue: 09 Volume: 65

Published: 24.09.2018 http://T-Science.org

\section{SECTION 20. Medicine}

Shafia Habib

WMO at THQ Pasrur district Sialkot Pakistan. shafia.habib93@yahoo.com

Amina Shabbir

WMO at THQ Daska, District Sialkot aminashabbir142@gmail.com

\title{
ABNORMAL PLACENTATION AND FETAL OUTCOME
}

\begin{abstract}
Objective: This study was done to determine fetal complications related to abnormal position of placenta.

Design and duration: This is an observational study of cross sectional type. Study duration was comprised on 6 months duration from January 2018 to July 2018.

Setting: Study was conducted in Gynecology and obstetrics ward of Nishter Hospital Multan, Pakistan.

Patients and Methods: patients for this study were selected from the gynae ward of the study institution. An inclusion and exclusion criteria was developed according to which all patients presenting in the study hospital during study period with placenta previa or abruption placenta were included in this study. Position of placenta was diagnosed on ultrasound done by consultant radiologist. Mothers having co-morbidities like pre-eclempsia, eclempsia, gestational diabetes, IHD or malignancy or tuberculosis etc were not included in the study. Only those cases were included which were admitted in the study hospital for delivery. Proper history about previous miscarriage or recently any complication or bleeding was asked. Examination was done and ultrasound abdomen done to know fetal well being. These cases were planned for cesarean section as normal delivery was complicated due to abnormal placenta position. All data was noted down on a performa and data was analyzed using statistical softwares Results calculated in the form of frequency and percentage and expressed in the form of table and graphs.
\end{abstract}

Results: Total 68 cases were included in this study falling on inclusion criterion. Age of these cases was ranging from 17-38 years with mean age of 24.2 14.5 years. There were 45 cases with abruption placenta and 23 with placenta previa out of total 68 cases. Among females with abruption placenta, there were $13 \%$ cases between 15-20 years, 26\% between 21-25 years, 21\% between 26-30 years, 30.4\% between 31-35 years and 8.7\% having age above 35 years. There were 11 still births, 6 from females with abruption placenta and 5 from females with placenta previa. There were total 39 premature births out of which $53.8 \%$ due to placenta abruptia and $46.2 \%$ due to placenta previa. Out of total 57 live births 25 were admitted in neonatal ICU. Maternal mortality rate was $5.9 \%$ and perinatal mortality rate was $56.4 \%$ in placenta abruptia and $43.6 \%$ in placenta previa. P-value was less than 0.05 .

Conclusion: Abnormal position of placenta is associated with high rate of fetal morbidity and mortality and complicated delivery indicating cesarean section. Most of the babies in this condition are premature.

Key words: Placenta abruptia, placenta previa, perinatal mortality, fetal outcome

Language: English

Citation: Liaqat H, Habib S, Shabbir A (2018) ABNORMAL PLACENTATION AND FETAL OUTCOME. ISJ Theoretical \& Applied Science, 09 (65): 129-133.

Soi: http://s-o-i.org/1.1/TAS-09-65-20 Doi: crossef https://dx.doi.org/10.15863/TAS.2018.09.65.20

\section{INTRODUCTION}

During pregnancy many physiological changes occur in female body making it compatible for fetus. ${ }^{1}$ Placenta provides nutrition to the fetus via blood and is a primary tissue on which it is dependent. There are many abnormal positions of placenta making gestational period complicated and associated with cesarean section and poor fetal outcome. ${ }^{2}$ There are also many maternal complications associated with abnormal placentation like pre-eclempsia and eclempsia, obstructed delivery, miscarriage and still birth etc. Females with abnormal placentation have spontaneous per vaginal bleeding and lower abdominal pain. ${ }^{3}$ Many cases are not diagnosed due to non utilization of antenatal care by females during pregnancy. Thre is lack of awareness among females of under developed areas of Pakistan. ${ }^{4}$ High illiteracy rate and high proportion of uneducated females is a most common factor in increasing perinatal mortality rate. During pregnancy females require proper 
antenatal visits in which history is taken about any complication like abdominal pain and per vaginal bleeding etc. Examination is done and ultrasound is done to confirm fetal viability. ${ }^{5}$ Females are taught about how to deal with problems in pregnancy and care, precautions etc.patients for this study were selected from the gynae ward of the study institution. An inclusion and exclusion criteria was developed according to which all patients presenting in the study hospital during study period with placenta previa or abruption placenta were included in this study. Position of placenta was diagnosed on ultrasound done by consultant radiologist. Mothers having co-morbidities like pre-eclempsia, eclempsia, gestational diabetes, IHD or malignancy or tuberculosis etc were not included in the study. Only those cases were included which were admitted in the study hospital for delivery. ${ }^{6}$ When pregnancy is complicated fetal growth is retarded and immature, Low birth weight, birth asphyxia and poor fetal health are common complications. These neonates require proper ICU care until their lungs mature. Neonates need resuscitation with oxygen therapy. Many times still birth happens in these cases or very weak immature neonate is borne which is less likely to survive.

\section{Patients and Methods}

Patients for this study were selected from the gynae ward of the study institution. An inclusion and exclusion criteria was developed according to which all patients presenting in the study hospital during study period with placenta previa or abruption placenta were included in this study. During pregnancy many physiological changes occur in female body making it compatible for fetus. Placenta provides nutrition to the fetus via blood and is a primary tissue on which it is dependent. There are many abnormal positions of placenta making gestational period complicated and associated with cesarean section and poor fetal outcome. Position of placenta was diagnosed on ultrasound done by consultant radiologist. Mothers having comorbidities like pre-eclempsia, eclempsia, gestational diabetes, IHD or malignancy or tuberculosis etc were not included in the study. Only those cases were included which were admitted in the study hospital for delivery. Proper history about previous miscarriage or recently any complication or bleeding was asked. Examination was done and ultrasound abdomen done to know fetal well being. These cases were planned for cesarean section as normal delivery was complicated due to abnormal placenta position. When pregnancy is complicated fetal growth is retarded and immature, Low birth weight, birth asphyxia and poor fetal health are common complications. These neonates require proper ICU care until their lungs mature. Neonates need resuscitation with oxygen therapy. Many times still birth happens in these cases or very weak immature neonate is borne which is less likely to survive. All data was noted down on a performa and data was analyzed using statistical softwares Results calculated in the form of frequency and percentage and expressed in the form of table and graphs.

\section{Results}

Total 68 cases were included in this study falling on inclusion criterion. Age of these cases was ranging from 17-38 years with mean age of $24.2 \pm 14.5$ years. There were 45 cases with abruption placenta and 23 with placenta previa out of total 68 cases. Among females with abruption placenta, there were $3(13 \%)$ cases between $15-20$ years, 6(26\%) between $21-25$ years, $5(21 \%)$ between $26-30$ years, $7(30.4 \%)$ between $31-35$ years and $2(8.7 \%)$ having age above 35 years. Patients for this study were selected from the gynae ward of the study institution. An inclusion and exclusion criteria was developed according to which all patients presenting in the study hospital during study period with placenta previa or abruption placenta were included in this study. During pregnancy many physiological changes occur in female body making it compatible for fetus. Placenta provides nutrition to the fetus via blood and is a primary tissue on which it is dependent. There were 11 still births, 6 from females with abruption placenta and 5 from females with placenta previa. There are also many maternal complications associated with abnormal placentation like pre-eclempsia and eclempsia, obstructed delivery, miscarriage and still birth etc. Females with abnormal placentation have spontaneous per vaginal bleeding and lower abdominal pain. Many cases are not diagnosed due to non utilization of antenatal care by females during pregnancy. There were total 39 premature births out of which $53.8 \%$ due to placenta abruptia and $46.2 \%$ due to placenta previa. Out of total 57 live births 25 were admitted in neonatal ICU. Maternal mortality rate was $5.9 \%$ and perinatal mortality rate was $22(56.4 \%)$ in placenta abruptia and $17(43.6 \%)$ in placenta previa. P-value was less than 0.05 . 


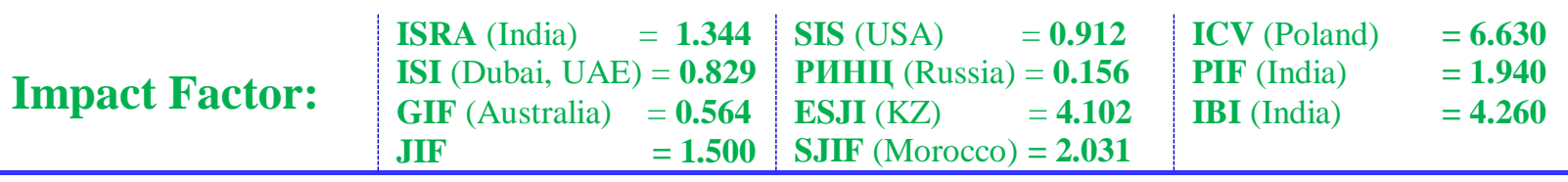

Age distribution of females in study group

Table-1

\begin{tabular}{|c|c|c|c|c|}
\hline $\begin{array}{c}\text { Ages of patients } \\
\text { (years) }\end{array}$ & \multicolumn{2}{|c|}{ Females with abruption placenta } & \multicolumn{2}{c|}{ Females with placenta previa } \\
\hline & $\mathbf{N}$ & $\mathbf{\%}$ & $\mathbf{N}$ & \% \\
\hline $15-20$ & 8 & 17.8 & 3 & 13 \\
\hline $21-25$ & 10 & 22.2 & 6 & 26.1 \\
\hline $26-30$ & 13 & 28.9 & 5 & 21.7 \\
\hline $31-35$ & 9 & 20 & 7 & 30.4 \\
\hline Above 35 & 5 & 11 & 2 & $\mathbf{1 0 0}$ \\
\hline Total & $\mathbf{4 5}$ & $\mathbf{1 0 0}$ & $\mathbf{2 3}$ & \\
\hline
\end{tabular}

Table-2

Fetal outcome related to abnormal placentation

\begin{tabular}{|l|c|c|c|c|}
\hline \multicolumn{1}{|c|}{ Fetal outcome } & \multicolumn{2}{|c|}{ Females with placenta abruption } & \multicolumn{2}{c|}{ Females with placenta previa } \\
\hline Premaurity & $\mathbf{N}=\mathbf{4 5}$ & $\mathbf{0}$ & $\mathbf{N = 2 3}$ & $\%$ \\
\hline Admitted in ICU & $\mathbf{2 1}$ & $\mathbf{5 3 . 8}$ & $\mathbf{1 8}$ & $\mathbf{4 6 . 2}$ \\
\hline Underweight & $\mathbf{3 2}$ & & 16 & \\
\hline Perinatal mortality & $\mathbf{2 7}$ & & 11 & \\
\hline
\end{tabular}

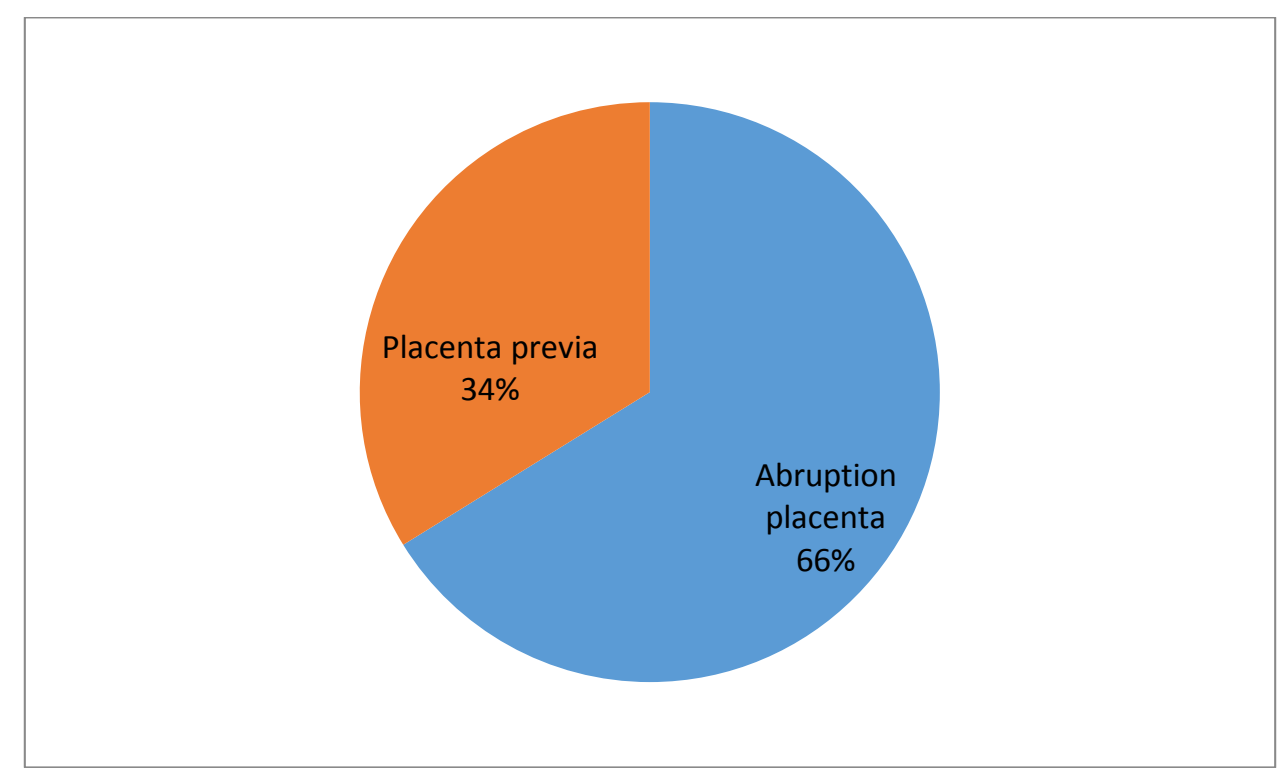

Figure-1 Frequency of abnormal placenta position in study group 


\begin{tabular}{|c|c|c|c|c|c|c|}
\hline Impact Factor: & $\begin{array}{l}\text { ISRA (India) } \\
\text { ISI (Dubai, UAE } \\
\text { GIF (Australia) } \\
\text { JIF }\end{array}$ & $\begin{array}{r}=1.344 \\
=0.829 \\
=0.564 \\
=1.500\end{array}$ & $\begin{array}{l}\text { SIS (USA) } \\
\text { PИНЦ (Russia) } \\
\text { ESJI (KZ) } \\
\text { SJIF (Morocco) }\end{array}$ & $\begin{array}{l}=0.912 \\
=0.156 \\
=4.102 \\
=2.031\end{array}$ & $\begin{array}{l}\text { ICV (Poland) } \\
\text { PIF (India) } \\
\text { IBI (India) }\end{array}$ & $\begin{array}{l}=6.630 \\
=1.940 \\
=4.260\end{array}$ \\
\hline
\end{tabular}

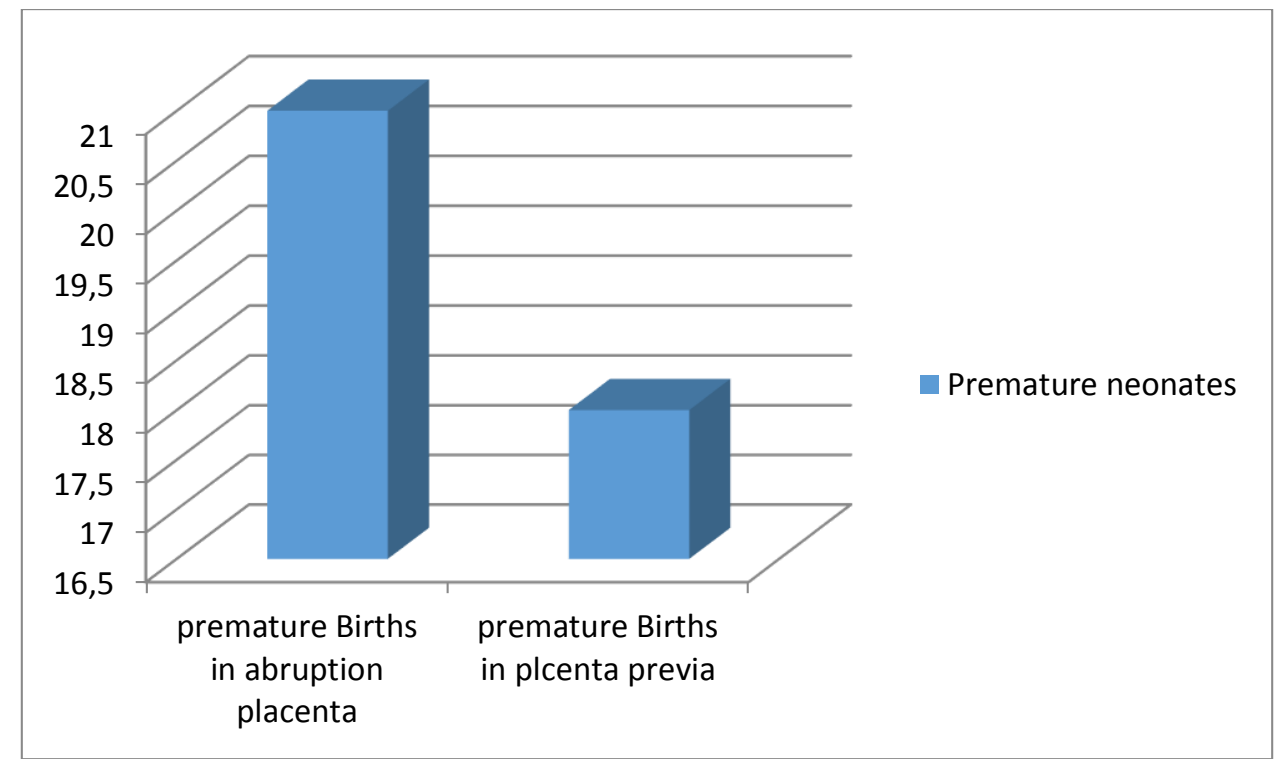

Figure-2 Frequency of premature births in placenta previa and placenta abruption

\section{DISCUSSION}

Fetus gets its nutrition from the mother via placental tissue. Placenta in normal position is favourable for gestation but when it is present in abnormal position then it causes complications such as premature birth of baby, immature or underweight newborn, need of cesarean section, increased perinatal morbidity and mortality rate and increased maternal morbidity and mortality rate. $^{7}$ Placenta previa and placenta abruption are two most common abnormal positions of placenta. In these situations cesarean is planned as spontaneous vaginal delivery is risky. More blood loss and intra operative complication rate is high. Due to underdeveloped fetus its survival rate is low. Neonatal ICU care is provided to newborn. ${ }^{8}$ During pregnancy many physiological changes occur in female body making it compatible for fetus. Placenta provides nutrition to the fetus via blood and is a primary tissue on which it is dependent. There are many abnormal positions of placenta making gestational period complicated and associated with cesarean section and poor fetal outcome. ${ }^{9-12}$ There are also many maternal complications associated with abnormal placentation like pre-eclempsia and eclempsia, obstructed delivery, miscarriage and still birth etc. Females with abnormal placentation have spontaneous per vaginal bleeding and lower abdominal pain. Many cases are not diagnosed due to non utilization of antenatal care by females during pregnancy. Patients for this study were selected from the gynae ward of the study institution. ${ }^{13,14}$ An inclusion and exclusion criteria was developed according to which all patients presenting in the study hospital during study period with placenta previa or abruption placenta were included in this study. During pregnancy many physiological changes occur in female body making it compatible for fetus. Placenta provides nutrition to the fetus via blood and is a primary tissue on which it is dependent. ${ }^{15}$ There are many abnormal positions of placenta making gestational period complicated and associated with cesarean section and poor fetal outcome. There were total 39 premature births out of which $53.8 \%$ due to placenta abruptia and $46.2 \%$ due to placenta previa. Out of total 57 live births 25 were admitted in neonatal ICU. Maternal mortality rate was $5.9 \%$ and perinatal mortality rate was $22(56.4 \%)$ in placenta abruptia and $17(43.6 \%)$ in placenta previa. P-value was less than 0.05 . Position of placenta was diagnosed on ultrasound done by consultant radiologist. Mothers having comorbidities like pre-eclempsia, eclempsia, gestational diabetes, IHD or malignancy or tuberculosis etc were not included in the study. ${ }^{16-17}$ Mothers having co-morbidities like pre-eclempsia, eclempsia, gestational diabetes, IHD or malignancy or tuberculosis etc were not included in the study. Only those cases were included which were admitted in the study hospital for delivery. When pregnancy is complicated fetal growth is retarded and immature, Low birth weight, birth asphyxia and poor fetal health are common complications. 


\begin{tabular}{l|lr|ll|ll} 
& ISRA (India) & $=\mathbf{1 . 3 4 4}$ & SIS (USA) & $=\mathbf{0 . 9 1 2}$ & ICV (Poland) & $=\mathbf{6 . 6 3 0}$ \\
Impact Factor: & ISI (Dubai, UAE) $=\mathbf{0 . 8 2 9}$ & PUHL (Russia) $=\mathbf{0 . 1 5 6}$ & PIF (India) & $=\mathbf{1 . 9 4 0}$ \\
& GIF (Australia) & $\mathbf{0 . 5 6 4}$ & ESJI (KZ) & $=\mathbf{4 . 1 0 2}$ & IBI (India) & $=\mathbf{4 . 2 6 0}$ \\
& JIF & $=1.500$ & SJIF (Morocco) & $=\mathbf{2 . 0 3 1}$ & & \\
\hline
\end{tabular}

\section{References:}

1. Chan CC, To WW. (1999) Antepartum haemorrhage of unknown origin- what is its clinical signifi cance? Acta Obstet Gynaecol Scand 1999; 78:186-190.

2. Ananth CV, Smulian JC, Demissie K, Vintzileos AM, Knup-pel RA. (2001) Placental abruption in singletone and twin births in United States: risk factors profi les. Am J Epidemiol 2001; 153: 771-8.

3. Ananth CV, Berkowitz GS, Savitz DA, Lapinski RH. (1999) Placen-tal abruption and adverse perinatal outcomes. JAMA 1999; 282:1646-51.

4. Ananth CV, Wilcox AJ. (2001) Placental abruption and perinatal mor-tality in the United States. Am J Epidemiol 2001; 153: 332-7.

5. Sheiner E, Shoham-Vardi I, Hardar A, Hallak M, Hackmon R, Mazor M. (2002) Incidence, obstetric risk factors and pregnancy out-come of preterm placental abruption: a retrospective analysis. J Metern Fetal Neonatal Med 2002; 11: 34-9.

6. Tuzovic L, Djelmis J, Llijic M. (2003) Obstetric risk factors associated with placenta previa development; case control study. Croat Med J. 2003; 44: 728-33.

7. Gilliam M, Rosenberg D, Davis F. (2002) The likelihood of placenta previa with greater number of cesarean deliveries and high parity. J Obstet Gynaecol 2002; 99: 976-80.

8. Abu-Heija A, EL-Jallad F, Ziadeh S. (1999) Placenta previa: effect of age, gravidity, parity and previous cesarean section. Obstet Gynaecol Inv 1999; 47: 6-8.

9. Ananth CV, Smulian JC, Vintzielos A. (1997) The association of pla-centa previa with history of cesarean delivery and abortion: a meta analysis. Am J Obstet Gynaecol 1997; 177:1071-8.

10. Weerasekera DS. (2000) Placenta previa and scard uterus - an obstetri-cian's dilemma. J Obstet Gynaecol 2000; 20: 484-85.

11. Macones GA, Sehdev HM, Parry S, Morgan MA et al. (1997) The as-sociation between maternal cocaine use and placenta previa. Am J Obstet Gynecol 1997; 177:1097-100.

12. Francois K, Johnson JM, Harris C. (2003) Is placenta previa more common in multiple gestation? Am J Obstet Gynecol 2003; 188:1226-7.

13. Goswami K, Thornton S. (2007) The prevention and treatment of pre-term labour. Studd J. Progress in obstetrics and gynaecology. 2007; 17: 217-30.

14. Hack M, Flannery DJ, Schluchter M, Cartar L, Borawski E, et al. (2002) Outcomes in young adulthood of very low birth weight in-fants. N Engle J Med 2002; 346: 149-57.

15. Sarwar I, Abbasi A, Islam A. (2006) Abruptio placenta and its compli-cation at Ayub Teaching Hospital, Abbottabad. J Ayub Med Coll. 2006;18: 27-31

16. Ananth CV, Savitz DA, Williams MA. (1996) Placental abruption and its association with hypertension and prolonged rupture of membranes; a methadologic review and metaanalysis. Ob-stet Gynecol 1996; 88: 309-18.

17. Ananth CV, Oyelese Y, Yeol, et al. (2005) Placental abruption in the United States. 1979 through 2001; temporal trend and poten-tial determinants. Am J Obstet Gynaecol 2005; 192: 191-98. 